\title{
Arranjos institucionais e capacidades de governo em processos participativos de urbanização: o caso de São Bernardo do Campo - SP
}

\author{
Liliane Araujo Barbosa \\ Universidade de São Paulo (USP) \\ José Carlos Vaz \\ Universidade de São Paulo (USP)
}

Nas últimas décadas, os projetos urbanos e habitacionais passaram a prever a participação da população nas intervenções. Iniciativas como os projetos de urbanização do Programa de Aceleração do Crescimento (PAC) do Governo Federal brasileiro fortaleceram essa tendência, estimulando a criação de arranjos federativos e institucionais no interior dos municípios para possibilitar sua implantação, ensejando o protagonismo social e a inclusão dos moradores no processo. A complexidade dessas iniciativas requer dos municípios capacidades para implementar políticas habitacionais que tenham a participação popular como item indispensável em sua consecução. Este artigo busca identificar e analisar quais são essas capacidades relacionadas ao arranjo institucional adotado, a partir da construção e implementação do Projeto de Urbanização PAC Alvarenga, que inclui a área de reassentamento do Conjunto Habitacional Três Marias, em São Bernardo do Campo, por meio da metodologia de estudo de caso. As capacidades encontradas foram organizadas em quatro categorias: capacidades políticas, técnicas, administrativas e institucionais.

Palavras-chave: arranjos institucionais, política habitacional, urbanização, desenvolvimento sustentável, participação social, capacidade estatal

[Artigo recebido em 25 de junho de 2018. Aprovado em 22 de fevereiro de 2019.] 
Arregalos Institucionales y capacidades de gobierno en procesos participativos de urbanización: el caso de San Bernardo Del Campo - SP

En las últimas décadas, los proyectos urbanos y habitacionales pasaron a prever la participación de la población en las intervenciones. Las iniciativas como los proyectos de urbanización del PAC (Programa de Aceleración del Crecimiento) del gobierno federal brasileño fortalecieron esa tendencia, estimulando la creación de arreglos federativos e institucionales en el interior de los municipios para posibilitar su implantación dando lugar al protagonismo social y la inclusión de los habitantes en el proceso. La complejidad de estas iniciativas requiere de los municipios capacidades para implementar políticas habitacionales que prevean la participación popular como requisito. Este artículo busca identificar y analizar cuáles son las capacidades relacionadas al arreglo institucional adoptado, demandadas por la construcción e implementación del Proyecto de Urbanización PAC Alvarenga, que incluye el área de reasentamiento del Conjunto Habitacional Tres Marias, en San Bernardo del Campo. El trabajo se configuró como un estudio de caso interpretativo. Se verificó la existencia de capacidades directamente relacionadas con la configuración del arreglo institucional, que se organizaron en cuatro categorías: capacidades políticas, técnicas, administrativas e institucionales.

Palabras clave: arreglos institucionales, política de vivienda, urbanización, desarrollo sostenible, participación social, capacidad estatal

\section{Institucional arrangements and governance capacities in participatory urbanization processes: the case of São Bernardo do Campo - SP}

In the last decades, the urban and housing projects began to predict the participation of the population in the interventions. Initiatives such as the PAC's (Growth Acceleration Program) urbanization projects have strengthened this trend, stimulating the creation of federative arrangements and institutional arrangements within the municipalities to enable their implementation, fostering social protagonism and inclusion of the residents in the process. The complexity of these initiatives requires that municipalities have the capacity to implement housing policies that provide for popular participation as an indispensable element in their achievement. This article seeks to identify and analyze what these capacities are related to the institutional arrangement adopted, based on the construction and implementation of the PAC Alvarenga Urbanization Project, which includes the resettlement area of the Três Marias Housing Complex, in São Bernardo do Campo, through the methodology case study. The capacities encountered were organized into four categories: political, administrative and institutional capacities.

Keywords: institutional arrangements, housing policy, urbanization, sustainable development, social participation, state capacity 


\section{Introdução}

As políticas habitacionais do Governo Federal no período 2002-2015 foram marcadas pela articulação federativa, com envolvimento do Governo Federal nas dimensões de formulação geral da política, financiamento e estabelecimento de normas, cabendo aos entes federados, especialmente aos municípios, a sua implementação no território. Arranjos institucionais complexos, em nível federativo, foram desenhados para essas políticas, envolvendo ministérios, a Caixa Econômica Federal, governos estaduais e municipais, movimentos sociais e empresas do setor imobiliário e da construção civil. Os municípios, por sua vez, também precisaram constituir arranjos institucionais em seu território para dar conta dos desafios da implementação das políticas.

Em função do que está estabelecido na Constituição Federal e no Estatuto da Cidade (Lei no 10.257/2001), a institucionalização do processo participativo é colocada como premissa das políticas urbanas e habitacionais, ainda que sua adoção seja sujeita a limitações e a graus distintos de adesão por parte dos governos municipais (ROLNIK, 2011). Para os municípios cujos governos procuraram em alguma medida atender a essa diretriz, o processo de implementação da política habitacional torna-se ainda mais complexo.

Partindo-se do pressuposto de que o Estado necessita de capacidades específicas para que a implementação de políticas habitacionais com participação da sociedade ocorra, faz-se premente levantar a questão sobre quais são as capacidades demandadas.

Este artigo tem como objetivo contribuir, a partir de um caso concreto, para a identificação dos tipos de capacidades demandadas dos governos municipais para que a implementação de projetos de urbanização com participação da sociedade se desenvolva. Dada a complexidade deste objetivo, algumas escolhas foram feitas. A primeira diz respeito à diversidade das ações no campo da política habitacional: analisar suas várias formas exigiria um esforço de enorme vulto, o que levou a restringir o foco a um tipo específico de ação da política habitacional, os projetos de intervenção e urbanização de assentamentos precários do Plano de Aceleração do Crescimento (PAC) do Governo Federal. A segunda escolha foi concentrar-se nas capacidades relacionadas à criação e funcionamento de arranjos institucionais no nível local que permitam a realização das intervenções com participação social, tendo em vista a importância que estes encontram na literatura recente sobre capacidades estatais. Por fim, optou-se por não realizar avaliações do grau de profundidade, abrangência ou efetividade dos processos participativos, o que demandaria outro tipo de investigação. 
A partir dessas opções de pesquisa, o artigo orientou-se para responder à pergunta:

Quais são as capacidades demandadas aos governos municipais, em termos de arranjos institucionais, pela implantação de processos de participação nos projetos de urbanização vinculados ao PAC?

Responder a essa pergunta exigiu uma atenta revisão da literatura sobre capacidades estatais, capacidades de governo e arranjos institucionais, com especial atenção à literatura que tem articulado esses conceitos à experiência brasileira recente. A partir daí, adotou-se como estratégia a realização de um estudo de caso único: a implantação do projeto PAC Alvarenga, no município de São Bernardo do Campo (SP), no período de abril a dezembro de 2015.

A escolha do caso deveu-se à estrutura de gestão e execução da política urbana e habitacional do município, em especial à estruturação e aos processos de trabalho da Secretaria de Habitação, e, por fim, às intervenções realizadas.

A seção seguinte a esta introdução visita a literatura sobre capacidades estatais, capacidade de governo e arranjos institucionais, em busca da construção de um referencial para a investigação de campo. A terceira seção apresenta o caso estudado e a quarta, as escolhas de estruturação da pesquisa em termos de método e análise dos dados. Segue-se uma seção de discussão dos resultados, em que as capacidades identificadas são analisadas à luz da literatura. Por fim, a última seção apresenta as conclusões do estudo.

\section{Governo, capacidades e arranjos institucionais}

O conceito de capacidade em suas várias formas (capacidade estatal, capacidade institucional, capacidade de governo, entre outras) tem caráter polissêmico e complexo, o que possibilita que seja utilizado com pressupostos diferentes nos diversos objetos. De acordo com Skocpol (1985), a capacidade estatal é entendida como a implementação das metas e objetivos formulados pelo Estado, mesmo com a oposição de grupos sociais.

Skocpol (1985) defende que o Estado é um ator capaz de formular e perseguir intenções e objetivos construídos a partir de seus próprios interesses, não sendo, portanto, um agente que meramente reflete as demandas de grupos sociais.

Evans, Rueschemeyer e Skocpol (1985) concebem o Estado como um ator e, ao mesmo tempo, um "meio" determinante, ou seja, os arranjos institucionais irão influenciar ideias e comportamentos políticos dos grupos sociais. Para Skocpol (1985, p. 14), as ações do Estado são historicamente determinadas, sendo "sensíveis às variações estruturais e mudanças conjunturais dentro do sistema político". 
Pereira (2014) ressalta que os estudos primevos apresentavam uma visão mais limitada da capacidade estatal, bastante influenciada pela concepção weberiana de burocracia qualificada e autônoma. Essas análises trazem pontos importantes acerca do Estado e de suas capacidades, a saber: a heterogeneidade do Estado e a relevância da coordenação intraestatal. Reconhece-se que o isolamento estatal é insuficiente para a compreensão das capacidades e que é necessário analisar a relação Estado-sociedade para que o entendimento sobre a capacidade estatal seja aprimorado.

A coordenação interburocrática é considerada um importante elemento da capacidade estatal, estando presente nas obras de influência weberiana como a de Rueschemeyer e Evans (1985). Ela significa a capacidade que diversas organizações governamentais teriam em seguir uma mesma diretriz, afastando-se das influências externas. Diante desse quadro, a descentralização das atividades entre diversas burocracias tenderia a gerar fragmentação e a possibilidade de cooptação do Estado pelos diversos interesses disseminados na sociedade (PEREIRA, 2014). Sendo assim, o Estado só poderia executar suas preferências isolando-se, porém, conforme salientado por Dagnino (2004), o Estado não é um todo homogêneo: nele estão presentes diversos interesses provenientes de diversos atores.

Nos anos 1990, o conceito de capacidade estatal passa por reformulações que ampliam seu alcance. Para Huerta (2008), a nova orientação busca dar ao Estado a direção para um "bom governo", buscando executar políticas com mais eficiência, seguindo as demandas da sociedade, pautando-se por ações mais transparentes e na gestão dos recursos mais equilibrada.

O conceito de capacidade estatal passa a ter como pilar as trocas e interações provenientes da relação entre Estado e sociedade (CINGOLANI, 2013). Nesse momento, uma nova discussão surge: qualquer que seja a definição dada à capacidade estatal, seu significado não deveria limitar-se aos aspectos técnicoadministrativos da burocracia, ou seja, não deveria encerrar-se, unicamente, nas questões internas ao Estado, tais como a sua coordenação, autonomia, capacidade técnica, entre outros. Essa nova abordagem não relega as características da perspectiva anterior, mas soma a elas o aspecto político.

Huerta (2008) afirma que a capacidade estatal é formada por dois componentes: o administrativo e o político. A capacidade administrativa se relaciona às características técnico-burocráticas necessárias para que o Estado consiga operacionalizar seus objetivos. Essa capacidade é formada pelas dimensões de recursos humanos (relacionado aos cargos, salários e forma de recrutamento da burocracia) e organizacionais (referente aos recursos financeiros). Para a autora, a capacidade administrativa abrangeria a coordenação interburocrática e a interação 
intergovernamental, pois estas não sofreriam influências da sociedade, sendo considerados elementos internos ao Estado. A capacidade política é delimitada pela interação política entre os atores que compõem o Estado e os setores socioeconômicos.

Evans (1993) investiga as características do Estado desenvolvimentista, caracterizado por realizar transformações estruturais em busca do crescimento econômico. A visão estabelecida pelo autor sobre a capacidade estatal traz a capacidade administrativa-weberiana aliada ao relacionamento socioestatal.

Schneider (2014) e Evans (1993) têm em comum a visão de que o país possui diferentes modus operandi na condução ao desenvolvimento. Para Schneider (2014), essa variação é explicada pelas diferentes capacidades existentes na burocracia brasileira, o que pode ser explicado pela arena complexa que se tornou o Estado brasileiro. Os sucessivos governos desenvolvimentistas criaram diversas agências, instituições e políticas, onde havia diferentes grupos com diferentes interesses sem uma coerente coalizão ou estratégia de desenvolvimento.

Castro Santos (1997) agrega novos elementos na conformação da capacidade, ao incluir a relação política - relações entre o Estado e a sociedade, nas quais o Estado deve encontrar soluções para as demandas sociais. A autora não utiliza o conceito de capacidade estatal, mas capacidade governativa, pois este conceito dialoga com as ideias de governabilidade e governança, que se ligam às ações de governo, enquanto materialização do exercício da autoridade, controle, articulações realizadas, entre outros.

Diniz $(1996 ; 1998)$ pontua que a eficácia na ação governamental ocorrerá quando a eficiência não estiver ligada unicamente aos quesitos técnicos da burocracia, mas também à sustentabilidade das ações governamentais, as quais passariam sob o crivo da sociedade.

Matus (2007) utiliza o conceito de capacidade de governo como a

(...) capacidade de condução ou direção e refere-se ao acervo de técnicas, métodos, destrezas e habilidades de um ator e de sua equipe de governo para conduzir o processo social a objetivos declarados, dados a governabilidade do sistema e o conteúdo propositivo do projeto de governo (MATUs, 2007, p. 53).

A capacidade de governo está inter-relacionada ao projeto de governo e à governabilidade do sistema, são esses os três vértices que compõem o chamado triângulo de governo. O projeto de governo é resultado do processo normativo e das ações propostas. A governabilidade é conformada pelo sistema políticolegal, que envolve variáveis que se controlam e outras que não se controlam e são dependentes das ações dos demais atores. 
O conceito de capacidade de governo difere de outras abordagens por estar inserido de forma sistêmica e inter-relacional com os demais vértices. Isso faz com que o conceito se torne mais condizente com a complexidade presente nas ações governamentais. O ambiente político e situacional em que se insere uma ação governamental influencia a capacidade. Dessa forma, a capacidade deve ser entendida de um ponto de vista situacional. A partir dessa ideia, Vaz (2016) aponta a importância dos processos de ativação de capacidades, destacando que estas só existem uma vez que o governo é capaz de utilizá-las, caso contrário são apenas recursos ociosos. Tais processos estão diretamente associados à governabilidade.

Neste artigo, concebemos que o Estado é um ator, que se encontra em relação constante com os demais agentes, a saber, a sociedade, o sistema político-legal e burocrático, que o conforma, e as demais instituições com as quais se relaciona na implementação de uma determinada política.

\section{Capacidades estatais e arranjos institucionais no contexto brasileiro}

No período 2003-2015, o país retoma a postura de promotor de mudanças na estrutura econômica, com o Programa de Aceleração do Crescimento (PAC), e de promotor do desenvolvimento social. Essas mudanças ocorrem junto à dinamização da participação popular nas políticas públicas, a partir de diversos canais.

Gomide e Pires $(2011,2014)$ analisam as capacidades estatais com centralidade para o arranjo institucional. Este é entendido como "conjunto de regras, mecanismos e processos que definem a forma particular como se coordenam os atores e interesses na implementação de uma política específica" (GoMIDE; PIRES, 2014, p. 7). Para os autores, o arranjo concede ao Estado a capacidade para realizar suas políticas. Lotta e Vaz (2015) destacam o papel dos arranjos institucionais nessas novas práticas de governo, e afirmam que estes não seguem um padrão único. $A$ depender da política pública executada, assumirão traços específicos, devido aos atores envolvidos no processo, aos papéis exercidos por cada agente e ao contexto em que se configura.

Lotta e Favareto (2013), ao analisarem o PAC e outros programas, buscam, a partir dos arranjos institucionais, entender quais são as capacidades que o Estado mobiliza ao executar seus programas. Os arranjos são compostos por três elementos, a saber: a articulação intersetorial, a coordenação entre as esferas federativas e a sociedade civil para formar os modelos de gestão pública e, por fim, o enraizamento do programa no nível local de implementação. Esses três elementos são sintetizados pelos autores como integração horizontal - entre setores de políticas públicas - e integração vertical - entre entes federativos. Concluem que os programas possuem 
limitação na integração horizontal, que foram realizados por justaposição ou por integração temática e não por planejamentos ou por planos que perpassassem diferentes ministérios. Com relação à verticalidade, há a centralização na esfera federal, concedendo aos estados o papel de coadjuvantes e, aos municípios, envolvimento apenas na implementação.

Gomide e Pires (2011) sustentam que os arranjos institucionais variarão a partir da relação entre dois eixos de capacidades: o técnico-administrativo e o político. O primeiro é descrito como "a existência de organizações, instrumentos e profissionais competentes com habilidades de gestão" (GOMIDE; PIRES, 2011, p. 2), ou seja, é entendido como o conjunto de competências que os agentes estatais possuem para realizar suas políticas, conduzindo processos coordenados e voltados aos resultados. O segundo vincula-se à negociação de interesses e criação de consensos. A capacidade política demanda habilidades da burocracia para ampliar os canais de interlocução e negociação com os variados atores sociais, mediando conflitos e interesses (GOMIDE; PIRES, 2014, p. 19-20). Como elementos do eixo das capacidades técnico-administrativas, os autores citam a presença de capacidades como recursos humanos, financeiros e tecnológicos adequados e disponíveis; a existência de mecanismos de coordenação e estratégias de monitoramento. Para o eixo das capacidades políticas foram utilizados os seguintes critérios: as interações das burocracias do Executivo com os agentes do sistema político-representativos; a existência de canais de participação social efetivos e o controle realizado por órgãos internos ou externos.

Segundo os autores, há quatro combinações possíveis nos arranjos institucionais: alta capacidade técnico-administrativa e alta capacidade política; baixa capacidade técnico-administrativa e baixa capacidade política; alta capacidade política e baixa capacidade técnico-administrativa; e alta capacidade técnico-administrativa e baixa capacidade política. Assim, todo arranjo possuirá capacidade técnico-administrativa e política, porém os graus em que elas aparecerão nortearão os resultados de uma dada política.

Lotta e Favareto (2013), Lotta e Vaz (2015) e Gomide e Pires (2011, 2014) dão importância ao aspecto relacional presente nos arranjos político-institucionais. A relação entre Estado e sociedade traz inovações aos planos iniciais do governo, a partir das negociações entre os atores governamentais e a sociedade civil. Ao mesmo tempo, é necessário considerar elementos como a trajetória histórica dos setores governamentais, as instituições e os atores (GOMIDE; PIRES, 2014). 


\section{Capacidade de governo nos processos participativos de urbanização integrada}

Das análises realizadas por Pires e Gomide (2014), Matus (2007) e Stefani (2015), depreende-se a importância da dinâmica interna das instituições governamentais para a existência de capacidade de governo. Entretanto, a capacidade analisada de forma isolada ou independente não exprimirá a complexidade existente.

Cada processo participativo, nos diversos setores governamentais, segue dinâmicas institucionais e normas próprias. Seu desenvolvimento abarca histórias, atores e dinâmicas peculiares. Entretanto, mesmo com trajetórias institucionais diferentes, são possíveis semelhanças entre canais de participação. Dessa forma, podemos encontrar processos participativos que possuam as mesmas capacidades e os mesmos impasses (StefanI, 2015).

Com o intuito de verificar como se delimitam as capacidades governamentais referentes à interação com a sociedade nas instâncias participativas, neste caso as relativas ao processo de urbanização integrada, os conceitos de capacidade de governo desenvolvido por Matus (2007), os de capacidade política e técnicaadministrativa desenvolvidos por Pires e Gomide (2011, 2014) e a classificação realizada por Stefani (2015) fundamentaram a análise desenvolvida.

Esta pesquisa valeu-se das contribuições de Matus (2007), para adotar um conceito de capacidade de governo sistêmico e inter-relacional, colocando em evidência a fluidez da capacidade ao dialogar com o contexto e com os atores. A sua abordagem se relaciona ao contexto ramificado e entrelaçado do cenário da ação governamental, tornando-se mais adequada à realidade da administração pública.

Da obra de Gomide e Pires (2014, 2011), a abordagem dos arranjos institucionais na implementação de políticas públicas nos oferece um instrumento para a compreensão de como os atores e interesses se coordenam e se relacionam em um contexto democrático.

A partir dessa abordagem, este trabalho apoiou-se na categorização de capacidades realizada por Stefani (2015), por sua vez baseada no trabalho de Grindle (1996):

- Capacidades institucionais: âmbito legal e formal que dão suporte e estrutura às iniciativas de participação.

- Capacidade técnicas: são aquelas relacionadas ao desempenho das funções que envolvem o domínio de técnicas, recursos humanos, recursos financeiros, planejamento, gestão e organização.

- Capacidades administrativas: são aquelas que se relacionam às funções 
organizacionais e administrativas do governo, que devem dar suporte a todas as ações e projetos políticos.

- Capacidades políticas: referem-se às habilidades de negociação, diálogo com a sociedade, instituição de parcerias e mediação entre diversos atores.

Essas categorias foram adotadas como referencial para o trabalho. Houve convergência entre elas e os resultados das análises do estudo de caso. Entretanto, as subcategorias de capacidades veiculadas ao processo participativo em urbanização não coincidem com aquelas identificadas no estudo de Stefani (2015), devido às diferenças de objeto.

\section{O caso do PAC Alvarenga (São Bernardo do Campo)}

O Programa de Aceleração do Crescimento (PAC) trouxe investimentos em diversas áreas, tais como a infraestrutura, habitação, saneamento e a urbanização de assentamentos precários. Retoma a produção de uma Política Nacional de Habitação, na qual os governos subnacionais têm que se adequar à esfera federal sem, no entanto, contarem com significativos instrumentos de capacitação (SERAFIM, 2013).

No que se refere à urbanização, a multidisciplinaridade e a integração entre diferentes áreas e secretarias são pontos a serem considerados (BRASIL, 2010). A gestão participativa na decisão, implementação e avaliação dos projetos de urbanização integrada foi colocada como instrumento para equacionar a exclusão socioterritorial e, ao integrar a população no processo, conceder sustentabilidade à intervenção.

O trabalho social é um elemento central e possui como objetivo garantir a participação da população em todo o ciclo, desde a formulação à avaliação do projeto, com o intuito de adequar a intervenção às reais demandas da comunidade, por meio de um trabalho educativo que favoreça a organização comunitária, a educação sanitária e ambiental, a gestão comunitária e condominial e a realização de ações voltadas à geração de renda e o acesso ao trabalho. Esses fatores favoreceriam a sustentabilidade do projeto a ser executado.

O caso do projeto PAC Alvarenga, em São Bernardo do Campo, representa uma intervenção em que esses princípios foram considerados no desenho e implantação. De antemão esclarecemos que o trabalho social desenvolvido seguiu os parâmetros estabelecidos nas normativas do Ministério das Cidades, o que nos leva a concluir que o papel do município se enquadra em algo definido a priori. Essa formatação do trabalho vincula-se ao quesito financeiro, uma vez que os desembolsos para sua execução ocorrem, somente, se seguirem as diretrizes postas.

Dentre os bairros pertencentes à área de manancial da cidade, o bairro Alvarenga possui o maior contingente populacional e a maior densidade habitacional, 
representando cerca de $30 \%$ da população residente em mananciais. Possui importância na produção hídrica e na vegetação natural (ITIKAWA, 2008), assim como apresenta alta vulnerabilidade social.

Os assentamentos irregulares e precários no bairro Alvarenga surgiram na década de 1970, com a construção da Rodovia Imigrantes. Estes se instalaram próximo à represa, às margens da Rodovia e da Estrada dos Alvarenga.

Antes do PAC, a região foi objeto do Programa de Assistência Técnica ao Programa Saneamento para Populações em Áreas de Baixa Renda (PAT-PROSANEAR). Esse programa previa "apoiar técnica e financeiramente, na elaboração de programas e projetos sustentáveis, e execução de projetos para a recuperação urbana e ambiental de Núcleos do Bairro Alvarenga, favelas selecionadas em São Bernardo" (SÃo BERNARDo do CAMPo, 2015, p. 262).

Em 2007, ano de criação do PAC, as áreas do PAT-PROSANEAR foram definidas como prioritárias para investimento. Apenas em 2009, quando Luiz Marinho (PT) assume a gestão do município, foi realizada a revisão e atualização dos projetos de arquitetura, urbanismo e engenharia com as adequações previstas no PAC. A antiga Secretaria de Habitação e do Meio Ambiente foi dividida em Secretaria de Habitação e Secretaria de Gestão Ambiental. O cargo de secretária de habitação foi atribuído a Tássia de Menezes Regino, assistente social com experiência nos projetos de trabalho social e participação comunitária em urbanização e habitação de interesse social, coordenando equipes multidisciplinares e desenvolvendo atividades de articulação político-institucional. Ela havia atuado como consultora na elaboração do projeto técnico social e de reassentamento da região do núcleo Alvarenga, vinculado ao Programa de Assistência Técnica ao Programa Saneamento para Populações em Áreas de Baixa Renda (PAT-PROSANEAR) de 2004 a 2006.

O Projeto de Trabalho Social (PTS) apresentado no PAC Alvarenga, aprovado pela CAIXA, concentrava as intervenções em duas áreas: Sítio Bom Jesus e Conjunto Habitacional Três Marias. O projeto prevê que a participação seja desenvolvida em todas as fases do projeto, tendo-se a comunidade como coexecutora do projeto. Dentre os objetivos específicos delimitados no projeto, destacamos: a participação da comunidade em todas as decisões, monitoramentos, acompanhamentos e avaliações, as lideranças seriam capacitadas e haveria o estímulo a que outros moradores se tornassem líderes de suas comunidades e o projeto viabilizaria meios de comunicação que assegurariam o acesso às informações por todos os moradores.

A participação popular é descrita como a diretriz de condução do trabalho técnico social, "sendo ao mesmo tempo um objetivo a ser alcançado e um meio para realizar os outros objetivos" (SÃo BERNARDO DO CAMPO, 2015, p. 285). A participação popular é concebida como um processo a ser desenvolvido em todas 
as etapas do projeto, visando ao "(...) desenvolvimento social da comunidade" (SÃo BERNARDO DO CAMPO, 2015, p. 285), mas também como meio para garantir a sustentabilidade das obras e do novo habitat a ser construído.

\section{Metodologia}

Para cumprir o objetivo de contribuir na identificação dos tipos de capacidades demandadas dos governos municipais para a implementação de processos de urbanização com participação da sociedade, realizou-se um estudo de caso instrumental único.

A opção está fundamentada na distinção feita por Stake (2001). O interesse no caso está na contribuição que pode trazer à construção e aprofundamento de uma construção teórica (no caso, sobre as capacidades estatais e de governo). Os fatores que contribuíram para a escolha do caso foram as mudanças na estrutura de gestão e execução das políticas habitacionais e urbanas do município, consideradas iniciativas de construção e ativação de capacidades.

A pesquisa seguiu uma abordagem qualitativa, com o intuito de realizar uma análise que permitisse identificar elementos e relações para os quais não existem medidas objetivas e quantificáveis. Essa abordagem permitiu uma visão mais aprofundada das capacidades de governo no projeto de urbanização do PAC Alvarenga, considerando, inclusive, as contradições, incompletudes e relações de intercausalidade complexa.

As fontes de informação empregadas foram a análise documental (Projeto de Trabalho Social, relatórios e outros documentos oficiais da Prefeitura de São Bernardo do Campo, da CAIXA e do Ministério das Cidades), entrevistas com moradores beneficiários do projeto e profissionais envolvidas em sua implementação e a observação direta de reuniões do projeto. No que concerne ao uso do termo profissionais, esclarecemos que a equipe executora do trabalho social era formada por pessoas do sexo feminino.

O estudo de caso analisado requereu apreender comportamentos e acontecimentos, para tanto necessitou de familiarização com o ambiente a ser estudado. A observação direta foi uma técnica que possibilitou atingir esses resultados. O crivo para a escolha dos atores baseou-se na presença e atuação durante a elaboração e implementação do projeto na área. Tanto o corpo técnico quanto os moradores foram citados nos documentos analisados e/ou durante as entrevistas e na percepção adquirida durante a observação em campo. As entrevistas foram conduzidas seguindo um roteiro semiestruturado, com questões abertas e o roteiro flexível. 
O tratamento e análise dos dados orientaram-se por uma perspectiva interpretativista, que buscou "desenvolver a compreensão da realidade social que os sujeitos experimentam" (RODRIGUES, 2004, p. 86), considerando os fundamentos e finalidades das ações dos indivíduos, entendidos como participantes da construção da realidade social.

Os esforços de categorização realizados por Grindle (1996) e Stefani (2015) serviram como base para identificar, em campo, as capacidades requeridas à prefeitura pelo processo participativo no programa de urbanização.

Nas transcrições das entrevistas, nas notas de campo e nos documentos utilizados, foram identificadas, de maneira indutiva, unidades de conteúdo, devidamente codificadas. A partir da classificação das unidades por afinidade, surgiram blocos de capacidades que foram organizados de acordo com as categorias inspiradas na literatura. Os blocos de capacidades foram denominados subcategorias das respectivas categorias. Essas subcategorias foram também classificadas de acordo com a presença de uma relação direta com o arranjo institucional adotado. Ao final da pesquisa, obtivemos o Quadro 1, que sintetiza as unidades de conteúdo.

\section{Quadro 1 - Categorias da capacidade de governo identificadas no caso estudado}

\begin{tabular}{|l|l|l|}
\hline \multirow{4}{*}{ Categorias } & Subcategorias & $\begin{array}{l}\text { Relação } \\
\text { com arranjo } \\
\text { institucional }\end{array}$ \\
\hline \multirow{4}{*}{ Capacidade institucional } & Normatização & Sim \\
\cline { 2 - 3 } & Canais institucionais de participação & Sim \\
\hline \multirow{4}{*}{ Capacidade administrativa política } & Direcionamento político & Sim \\
\cline { 2 - 3 } & Mobilização & Sim \\
\cline { 2 - 3 } & Lecursos financeiros & Sim \\
\cline { 2 - 3 } & Recursos físicos & Não \\
\cline { 2 - 3 } & Articulação intragovernamental & São \\
\hline \multirow{5}{*}{ Capacidade técnica } & Recursos humanos & Sim \\
\cline { 2 - 3 } & $\begin{array}{l}\text { Planejamento e gestão do processo } \\
\text { participativo }\end{array}$ & Sim \\
\cline { 2 - 3 } & Operação do processo participativo & Sim \\
\hline
\end{tabular}

Fonte: elaboração própria. 
Nas seções seguintes, apresentam-se, de forma sucinta, as capacidades de governo encontradas no processo participativo de urbanização do PAC Alvarenga, analisadas em suas subcategorias.

\section{Capacidades institucionais}

As capacidades institucionais são as que trazem as normas que orientam a participação social na administração pública, ou seja, evidenciam as diretrizes que norteiam e estruturam a forma como devem funcionar os espaços participativos. É a capacidade de fazer acontecer e valer as determinações que dispõem sobre a interação entre sociedade/Estado e seus objetivos. O cumprimento desses regulamentos, portarias e instruções normativas revela a existência de capacidades na esfera institucional.

\section{Normatização}

De uma forma geral, no que concerne à execução das normas, as profissionais entrevistadas concluíram que o trabalho executado seguiu as diretrizes preconizadas pelo Ministério das Cidades. As funcionárias da CAIXA, que acompanharam o projeto de trabalho social, esclareceram que as normas sempre foram cumpridas pelo Departamento de Trabalho Social da prefeitura de São Bernardo do Campo, entretanto, alguns assuntos ligados aos eixos de execução do trabalho social poderiam ter sido executados com mais detalhes e qualidade. Citaram, especificamente, as atividades ligadas à educação sanitária e ambiental.

As evidências citadas mostram as facilidades e dificuldades das assistentes sociais da esfera municipal em fazer cumprir as normas existentes. Um dos gargalos da execução do trabalho social e concomitantemente da execução de um trabalho participativo é a coexistência de normas e seus requisitos que destoam da capacidade existente em diversos municípios. Para as entrevistadas, as exigências das normas e a proposição dos eixos temáticos não são adequadas à realidade da gestão municipal. As normas são vistas como pouco práticas e dão margens a dúvidas. Ao mesmo tempo, consideram que as regras mostram, ao menos, um caminho a seguir.

Assim como na análise realizada por Lotta e Favareto (2013), podemos concluir que a integração vertical, ou seja, a articulação entre a esfera federal e municipal, nesse caso, também é identificada com o ente federal centralizando os elementos normativos e com ao ente local cabendo, somente, o papel de implementador. 


\section{Canais institucionais de participação}

Sobre a necessidade de implementação de esferas participativas, foram identificadas a Comissão de Urbanização e Legalização (Comul) e a existência da Comissão de Acompanhamento do Projeto (CAP), atuando como um canal representativo da comunidade nas questões gerais do projeto. A esses representantes eram relatadas as informações sobre o projeto, dito como um "primeiro desenho", que com o diálogo sofria alterações, de acordo com as demandas da comunidade. Além disso, estavam presentes nos plantões sociais, reuniões e assembleias acompanhando tanto as atividades do trabalho social quanto as das obras.

A CAP foi formada, no bairro Sítio Bom Jesus, durante a execução do projeto do PAT-PROSANEAR, que antecedeu o PAC Alvarenga, seguindo as especificações da participação comunitária. Atuou como um instrumento de gestão participativa para as decisões e acompanhamentos do projeto.

A Comul se estabeleceu no Sítio Bom Jesus na execução do PAC. Muitos de seus componentes já atuavam na CAP. Mesmo havendo necessidade legal de sua formação, instituída pela Lei Municipal no 5959/2009, que a responsabiliza por deliberar e acompanhar as políticas de urbanização e legalização, evidenciou-se que o papel da CAP é mais expressivo, devido à sua existência anterior. Já no Conjunto Habitacional Três Marias, não existiu nenhuma dessas comissões.

A partir das entrevistas, tornou-se claro que a existência da Comul cumpre seu quesito normativo, porém não possui tanta interferência na condução dos projetos. A CAP foi um meio de representação mais atuante.

\section{Capacidades políticas}

Essa subcategoria de capacidade de governo refere-se à incorporação do processo participativo na tomada de decisão e na condução do projeto de intervenção. Dessa forma, abrange os meios como são realizadas as negociações, os diálogos e as mediações entre as demandas e interesses diversos dos atores (a sociedade e os parceiros).

\section{Direcionamento político}

A participação foi um quesito incorporado à realização da intervenção urbana, envolvendo a forma pela qual se incluíram os moradores no processo que, por sua vez, revela a escolhas políticas adotadas na condução da intervenção. O processo contou com a participação dos moradores, desde o projeto inicial e, continuamente, na implementação, graças aos canais existentes. 
Um entrave relatado na execução do processo participativo foram as informações dissonantes que chegavam aos moradores, via vereadores da oposição, o que gerou desconfiança por parte dos moradores e demonstrou uma possível falta de capacidade de articulação com esses atores.

As capacidades técnicas são congruentes ao direcionamento político. A condução técnica facilitou o estreitamento das relações entre a Secretaria de Habitação e a população. A relação de proximidade estabelecida entre a comunidade e as assistentes sociais fez com que a participação dos moradores na mobilização da comunidade pudesse ser executada. Conforme exposto pelas assistentes, a clareza nas informações, ouvir os moradores e atendê-los fez com que o projeto tivesse credibilidade.

A participação foi voltada à informação sobre as atividades e, pontualmente, previu a deliberação conjunta. Tanto o direcionamento político quanto a gestão do processo participativo concentraram-se na participação informativa e na participação como escuta, tal como definida por Teixeira (2014).

\section{Liderança}

A liderança surgiu como capacidade relevante com a constatação da constante presença e da forma de atuação das assistentes sociais e da secretária de habitação nas duas áreas de execução do projeto. As assistentes sociais entrevistadas ressaltaram que a secretária imprimiu uma nova gestão à Secretaria de Habitação, por meio de contratações via concurso público, e sempre esteve presente na tentativa de articulação com outras secretarias municipais.

Já o prefeito do município, Luiz Marinho, foi citado algumas vezes. A visão dos moradores sobre ele é como uma espécie de garantidor do processo.

As entrevistas indicaram que a secretária dirigiu o processo com o objetivo de dar autonomia às assistentes sociais na condução do trabalho, o que fortaleceu o papel de liderança desempenhado.

A capacidade de liderança na condução do processo participativo foi crucial para a construção do formato do trabalho executado. O papel desempenhado pela secretaria de habitação possibilitou a tentativa de articulação com outras secretarias e a consulta direta ao Ministério das Cidades, quando havia algum óbice na execução dos projetos, sem ter a necessidade de passar a demanda pelo agente financeiro. Ademais, a forma de condução do trabalho e a possibilidade de novas contratações para a formação da equipe foi resultado de uma negociação e articulação com o Poder Executivo, na qual o papel da secretária foi decisivo. 


\section{Mobilização e comunicação do processo participativo}

A forma de mobilização seguida na gestão do processo participativo ocorreu com o auxílio da CAP para incentivar as pessoas a participarem. Como visto no item anterior, no aspecto da participação da população na mobilização da comunidade, a capacidade de liderança está ligada à capacidade de mobilização.

Além disso, os espaços de participação - plantões sociais semanais, reuniões e assembleias - foram instrumentos para comunicar as fases de implementação do projeto e espaços para possibilitar o diálogo.

\section{Capacidades administrativas}

As capacidades administrativas ligam-se, especificamente, às funções administrativas e organizacionais que dão suporte ao projeto de governo. São os elementos administrativos e organizacionais que estruturam todos os projetos e as ações governamentais, funcionando como quesitos operacionais demandados para que o Estado consiga promover a participação social nos projetos de urbanização. O governo municipal necessita de determinada organização para que a participação ocorra, sempre dialogando com as regras e determinações contidas nas portarias e instruções normativas do Governo Federal e da administração pública, de uma forma geral.

Na pesquisa, assubcategorias encontradasforam:articulação intragovernamental, alocação de recursos físicos e alocação de recursos financeiros. Entende-se que apenas a primeira está diretamente relacionada aos arranjos institucionais, portanto as demais não são objeto de análise mais detalhada.

\section{Articulação intragovernamental}

A participação de outras secretarias no processo participativo da urbanização foi pontual, sem que ocorresse interlocução contínua. Tanto os moradores quanto as profissionais envolvidas indicaram que a presença de outras secretarias na execução do trabalho foi pontual e/ou inexistente. Os documentos permitem perceber que a articulação existente se dava em momentos específicos, como, por exemplo, nos eventos realizados pela Secretaria de Habitação. Nestes, as demais secretarias foram convidadas a participar oferecendo serviços aos munícipes. Na maioria das vezes, citou-se a articulação pela sua ausência na condução do processo participativo. Com relação ao fomento à participação em outras instâncias participativas como, por exemplo, o Orçamento Participativo, as entrevistadas viam a tarefa como demanda de todas as secretarias. 
De uma forma geral, as profissionais entrevistadas disseram que a articulação poderia ampliar os horizontes de atuação e possibilitar a implementação de um trabalho social mais efetivo, concebendo novas metodologias e formas de atuar na comunidade, já que as informações concedidas teriam mais fidedignidade, bem como poderiam aproximar os cidadãos aos serviços da prefeitura como um todo. Dessa forma, a população saberia a quem demandar e as questões não ficariam, unicamente, a cargo da Secretaria de Habitação. Como resultado final, haveria mais efetividade e celeridade na execução das atividades.

A inarticulação deveu-se mais a um condicionante institucional: a forma de planejamento do governo municipal, que limita as secretarias às funções e prioridades de cada área. As secretarias e departamentos foram convidados a participar de algumas reuniões, com o objetivo de formularem o planejamento das ações conjuntas, porém as ações definidas não foram levadas adiante.

Não se encontraram evidências de condicionantes políticos para a existência da inarticulação entre as secretarias da Prefeitura de São Bernardo do Campo, ainda que estes não possam ser descartados.

\section{Capacidades técnicas}

As capacidades técnicas referem-se à dimensão cognitiva desenvolvida para o desenvolvimento do processo participativo. Contempla habilidades e conhecimento do corpo de funcionários que atuam no processo de urbanização. Dessa forma, essa dimensão é composta pelo método desenhado e sua adequação aos quesitos participativos e aos objetivos expressos no projeto.

\section{Recursos humanos}

A análise sobre os recursos humanos refere-se à disponibilidade, à qualidade dos profissionais e, nesse âmbito, à possibilidade de capacitação na condução do processo participativo no projeto de urbanização.

Os moradores apontaram que as técnicas possuíam conhecimento sobre o que estavam realizando, além de expressarem que o contato e a execução do trabalho tiveram como diretriz a relação direta com a população. A equipe composta possuía experiência pretérita no desenvolvimento do trabalho social em outros municípios da região metropolitana. A experiência daquelas que coordenaram o trabalho social, a saber, a coordenadora do trabalho social e a secretária de habitação, foi fundamental para o andamento do processo participativo.

Além da qualidade, outro ponto salientado foi a preocupação com a capacitação da equipe. Nos relatórios constam palestras e oficinas, em que todos da coordenação técnica social participaram. 
Contudo, um dos fatores que impõem limite à condução participativa e ao desenvolvimento do trabalho social é o número de funcionários da equipe própria. A contratação de profissionais via gerenciadora foi vista como algo positivo, mas com limites. Estabelece-se uma parceria, porém o tempo de trabalho da contratada limita-se ao arco temporal estabelecido em contrato, que muitas vezes não acompanha o período total de intervenção. De acordo com as entrevistadas, algumas ações não puderam ser realizadas ou foram postergadas, devido ao fato de a equipe ser reduzida e a demanda ser excessiva.

\section{Planejamento e gestão do processo participativo}

Ocorreram reuniões semanais entre os departamentos que estavam constantemente envolvidos na implementação da urbanização (Obras, Trabalho Social e Regularização Fundiária). Ocorria monitoramento das ações com o objetivo de esclarecer as intercorrências e realizar as reprogramações necessárias. Entretanto, percebe-se o descompasso entre o que era firmado em reunião e a execução das ações, durante os cinco anos de urbanização.

A observação direta permitiu notar que as coordenações se envolviam, apenas, nos momentos cruciais em que eram demandadas. Ao questionarmos as profissionais sobre os maiores obstáculos na condução do processo participativo e no desenvolvimento do trabalho social, elas apontaram os problemas das obras e a falta de participação deste setor nas regiões de intervenção. De acordo com os relatórios, o planejamento era realizado, as pendências eram discutidas, porém no momento da execução houve falhas e a falta de acompanhamento efetivo do processo como um todo.

Além das relações existentes com as outras coordenações, foi ressaltado que o trabalho desenvolvido pela terceirizada tornou-se um caminho produtivo para o trabalho, tanto na visão das contratadas quanto das pertencentes à administração direta. Evidencia-se que o planejamento do trabalho não foi segmentado em atividades específicas, o que é identificado como característica do planejamento da coordenação.

\section{Operação do processo participativo}

A subcategoria operação do processo participativo remete à forma como é organizada a participação, os feedbacks dados à comunidade e a avaliação do processo como insumo para mudanças na organização. Possui relação com a dimensão política: a forma de conduzir o processo participativo faz com que as relações entre a prefeitura e os moradores sejam facilitadas.

O processo participativo sujeitou-se a limitadores, seja de recursos humanos, seja de articulação, entre outros. Havia abertura para a participação e a construção 
de espaços em que a comunidade recebia informações e era escutada. Entretanto, os documentos não evidenciaram o controle social do processo de intervenção na área, nem a construção deliberativa dos processos, nem a avaliação pela comunidade das ações e dos canais de participação. Essas características poderiam ser fatores estruturantes da execução do projeto, pontos de redimensionamento e orientação das atividades futuras.

A participação deliberativa deu-se em momentos específicos e pontuais. As atividades planejadas, de acordo com os relatórios, possuíam um desenho inicial e eram concebidas sem interferência da população. A operação do processo participativo foi tratada como um meio para que a intervenção física ocorresse sem percalços. A conquista da autonomia e da inserção real dos munícipes recebeu menor importância.

\section{Considerações finais}

Neste artigo, foram identificadas onze subcategorias de capacidades relevantes para a implantação do projeto PAC Alvarenga, em São Bernardo do Campo. Destas, foram analisadas em profundidade nove, aquelas relacionadas ao arranjo institucional adotado. Essa seleção, por si, já adianta uma conclusão importante da pesquisa: a maioria das capacidades identificadas relaciona-se ao arranjo institucional, demonstrando sua relevância para a implantação do projeto, ainda que não se atribua a este a responsabilidade total por sucessos e insucessos.

A pesquisa deixa claro que os arranjos institucionais envolvendo o Governo Federal e a esfera municipal foram importantes na implantação do PAC Alvarenga. Ao primeiro cabe a definição de diretrizes, normas, formas e instrumentos de avaliação do trabalho desenvolvido. Ao município cabe a implementação, o que exige desdobrar o arranjo institucional em nível local por mecanismos de articulação e participação.

Se aplicássemos o modelo proposto por Pires e Gomide (2014), teríamos um quadro de alta capacidade político-institucional e alta capacidade técnico-administrativa.

As capacidades de governo não se apresentaram como uma construção prévia e totalmente harmônica. Não podem ser vistas como fixas. O contexto de sua composição as faz como uma colcha de retalhos. Por isso, devem ser interpretadas de um ponto de vista situacional: modificam-se, ao sabor do contexto político e da interação entre os atores.

As capacidades não estão claramente dispostas. Os limites que as encerram são tênues. Interligam-se, relacionam-se mutuamente. Essas relações demonstram que a análise sobre as capacidades de governo não pode limitar-se a modelos de alta rigidez. 
Os espaços de participação nos projetos urbanos e habitacionais funcionaram como meio estruturador da sustentabilidade das intervenções, a partir de processos de liderança, organização e mobilização comunitária. Construir a agenda participativa demandou esforços de gestão dos processos participativos. A participação dos moradores ensejou alterações incrementais e diárias no cotidiano das equipes.

As dificuldades de articulação entre as secretarias e de coordenação entre os departamentos da Secretaria de Habitação foram evidentes. Geraram obstáculos ao processo participativo, que puderam ser minimizados pela capacidade técnica, alicerçada no conhecimento e no direcionamento dado ao planejamento do trabalho social.

Numa administração pública ideal, em que não há escassez de recursos financeiros nem humanos, a integração entre as áreas proporcionaria a condução do processo participativo de forma mais adequada. Deparamo-nos com uma reflexão sobre a visão do gestor e das diversas situações-problemas que se colocam à administração pública. Quando questionamos sobre o porquê dessa situação, as respostas apontaram para o número reduzido de funcionários das secretarias e o volume de demandas específicas de cada área. Ao mesmo tempo, as limitações e os recursos potenciais estão colocados em diversas administrações, e a superação dos problemas depende também das capacidades que os governos municipais consigam ativar.

A institucionalização de um departamento de trabalho social assim como a composição de sua equipe e os recursos voltados às capacitações foram decisões que articularam aspectos técnicos e políticos em busca da viabilidade da execução do trabalho social. Ao serem colocados em prática, ativaram capacidades decisivas e, quando houve obstáculos, puderam-se reorientar as ações em busca dos resultados estipulados.

Isso não quer dizer que a institucionalização de um departamento ou uma lei sejam necessárias para que as ações ocorram em outros casos. Eles podem tornarse um recurso potencial, existente no âmbito legal, mas que não são mobilizados em busca da execução do projeto de governo, como a literatura aponta (VAZ, 2016). No caso estudado, a capacidade de governo esteve centrada principalmente no quesito técnico, relacionado ao conhecimento e experiência das gestoras e de suas equipes, além da presença constante do planejamento e controle das atividades. Ao iniciar essa pesquisa, foi aventada a possibilidade de a execução do trabalho participativo via terceirizada ser um indício de ausência de capacidade de governo. Entretanto, o trabalho permitiu perceber que o direcionamento dado na implementação está consoante com o que foi determinado na contratação. O trabalho terceirizado 
contribuiu para a existência das capacidades de governo para a implementação do projeto. Isso se deve à forma de condução do trabalho, via administração direta, que incorpora esses funcionários como parte do projeto a ser executado, não, apenas, como "tarefeiros".

Essas características expostas acima contribuíram para que a implementação do processo participativo fosse realizada, mesmo com as limitações existentes.

\section{Referências bibliográficas}

BRASIL. Ministério das Cidades. Ações integradas de urbanização de assentamentos precários. Brasília: Ministério das Cidades, 2010.

CASTRO SANTOS, Maria Helena de. Governabilidade, governança e democracia: criação de capacidade governativa e relações Executivo-Legislativo no Brasil pós Constituinte. Dados, v. 40, n. 3, p. 335-376, 1997.

CINGOLANI, L. The state of State capacity: a review of concepts, evidence and measures. WorkingPaper n. 53. Maastricht: UNO-MERIT, 2013.

COTTA, Tereza Cristina. Burocracia, capacidade de Estado e mudança estrutural. Texto para discussão n. 21. Brasília: Enap, 1997.

DAGNINO, E. Sociedade civil, participação e cidadania: de que estamos falando? In: MATO, D. (Coord.). Políticas de ciudadania y sociedad civil en tiempos de globalización. Caracas: Faces, Universidad Central de Venezuela, 2004. p. 95-110.

DINIZ, Eli. Governabilidade, governance e reforma do Estado: considerações sobre o novo paradigma. Revista do Serviço Público, v. 47, n. 2, p. 65-91, 1996.

DINIZ, Eli. Uma perspectiva analítica para a reforma do Estado. Lua Nova: Revista de Cultura e Política, v. 45, n. 1, p. 29-48, 1998.

Evans, Peter B. Transnational linkages and the economic role of the State: analysis of developing and industrialized nations in the post-world II period. In: EVANS, P.; ReusCheMEYEY, D.; SKOCPOL, T. Bringing the State back in. New York: Cambridge University Press, 1985.

Evans, Peter B. O Estado como problema e solução. Lua Nova: Revista de Cultura e Política, v. 28, n. 1, p. 1-29, 1993.

EVAnS, P.; ReuschemeYeY, D.; SKOCPOL, T. Bringing the State back in. New York: Cambridge University Press, 1985.

GoMIDE, Alexandre; PIRES, Roberto. Capacidades estatais para o desenvolvimento no século XXI. Boletim de Análise Político-Institucional / Instituto de Pesquisa Econômica Aplicada, 1 /2011. Brasília: Ipea, 2011.

GOMIDE, A.; PIRES, R. Capacidades estatais e democracia: arranjos institucionais de políticas públicas. Brasília: Ipea, 2014.

GRINDLE, M. Challenging the State: crisis and innovation in Latin America and Africa. Cambridge: Cambridge University Press, 1996. p. 1-12. 
HuERTA, Angelica Rosas. Una ruta metodológica para evaluar la capacidad institucional. Política y Cultura, v. 30, n. 1, p. 119-134, 2008.

ITIKAWA, Valdete Kanagusko. Mananciais e urbanização: recuperação ambiental na sub-bacia Billings: os bairros ecológicos em São Bernardo do Campo e São Paulo (1997 a 2007). São Paulo: Universidade Presbiteriana Mackenzie, 2008. Dissertação (Mestrado em Arquitetura e Urbanismo) - Universidade Presbiteriana Mackenzie, São Paulo.

LOtTA, Gabriela; Favareto, Arilson. O papel dos territórios nos novos arranjos institucionais brasileiros. In: CONGRESSO DO CENTRO LATIOAMERICANO DE ADMINISTRAÇÃO

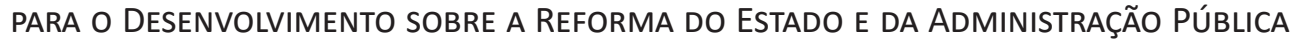
(CLAD), 18., 2013, Caracas. Anais... Caracas: Clad, 2013. p. 1-18.

LOTTA, Gabriela; VAZ, José Carlos. Arranjos institucionais de políticas públicas: aprendizados a partir do caso do Brasil. Revista do Serviço Público, v. 66, n. 2, p.171194, 2015.

MATUs, Carlos. Adeus, Senhor Presidente: governantes e governados. São Paulo: Fundap, 2007.

PEREIRA, Ana Karine. A construção de capacidade estatal por redes transversais: o caso Belo Monte. Brasília: UnB, 2014. Dissertação de Mestrado. Universidade de Brasília, Brasília.

PIRES, R.; GOMIDE, A. Arranjos institucionais e capacidades estatais na implementação de programas federais. In: ENCONTRO DA ABCP, 9., 2014, Brasília. Anais... Brasília: $A B C P$, 2014. p. 1-28.

Rodrigues, Andrea Leite. Metodologia. In: Rodrigues, Andrea Leite. Modelos de gestão e inovação social em organizações sem fins lucrativos: um estudo comparativo de casos no Brasil e no Quebec. São Paulo: FGV, 2004. Tese (Doutorado em Administração de Empresas) - Fundação Getúlio Vargas, São Paulo.

RoLNIK, Raquel. 10 anos do Estatuto da Cidade: das lutas pela reforma urbana às cidades da Copa do Mundo. 2011. Disponível em: < http://www.google.com.br/ url? sa $=t \& r c t=j \& q=\& e s r c=s \&$ source=web\&cd=1\&ved=0CB4QFjAA\&url=http\%3A \%2F\%2Fraquelr olnik.files. wordpress.com \%2F201 3\%2F07\%2F10-anos-do-estatut o-dacidade.pdf\&ei=brnXU6_xCq3nsAT_kIKgCQ\&usg=AFQjCNFTVdx9EPBIMo CpXn 4LMxJa8 DyBQ\&sig2 =YzJSqtJWsCZGjSRiYEgIKQ\&bvm=bv.71778758,d.cWc. $>$ Acesso em: 23/11/2016.

RUESCHEMEYER, D.; EVANS, P. The State and economic transformation: toward an analysis of the conditions underlying effective intervention. In: EVANS, P.; ReUSCHEMEYEY, D; SKOCPOL, T. Bringing the State back in. New York: Cambridge University Press, 1985.

SÃo BERNARDo Do CAMPo. Relatório de Trabalho Social - PAC Alvarenga. Referente a janeiro de 2009 a julho de 2015. 2015.

SCHNEIDER, Ben Ross. O Estado desenvolvimentista no Brasil: perspectivas históricas e comparadas. In: PIRES, Roberto Rocha; GoMIDE, Alexandre de Ávila (Eds.). Capacidades estatais e democracia. Brasília: Ipea, 2014. p. 31-56.

SERAFIM, Lizandra. Participação no governo Lula: as pautas da reforma urbana 
no Ministério das Cidades (2003-2010). Campinas: Universidade Estadual de Campinas, 2013. Tese (Ciência Política) - Instituto de Filosofia e Ciências Humanas da Universidade Estadual de Campinas, Campinas.

SKOCPOL, Theda. Bringing the State backing. In: EVANS, P.; REUSCHEMEYEY, D; SKOCPOL, T. Bringing the State back in. New York: Cambridge University Press, 1985.

StAKE, Robert E. Case Studies. In: Denzin, N.; Lincoln, Y. (Eds.). Handbook of Qualitative Research. 2. ed. London: Sage Publications Inc, 2001.

StEFANI, Anita G. M. Utilização de TICs em processos participativos no Brasil sob a ótica de capacidades de governo. São Paulo: USP, 2015. Dissertação (Gestão de Políticas Públicas) - Escola de Artes, Ciências e Humanidades, Universidade de São Paulo, São Paulo.

VAZ, José Carlos. Oportunidades de pesquisa e temas para reflexão sobre capacidades na gestão pública brasileira. In: OLIVIERI, C.; MARTINELLI, B. I. Colóquio de estudos em gestão de políticas públicas. São Paulo: EACH, 2016.

\section{Liliane Araujo Barbosa}

Possui mestrado em Gestão de Políticas Públicas pela Universidade de São Paulo (USP). Atualmente é servidora da Caixa Econômica Federal. Contato: lab85@hotmail.com

\section{José Carlos Vaz}

Possui doutorado em Administração de Empresas pela Fundação Getulio Vargas (FGV). Atualmente é professor da Universidade de São Paulo (USP). Contato: vaz@usp.br. 